\title{
Association of vitamin D status at birth and respi- ratory outcomes in preterm infants
}

\author{
Sook-Hyun Park, MD, PhD ${ }^{1,2}$ \\ ${ }^{1}$ Department of Pediatrics, School of Medicine, Kyungpook National University, Daegu, ${ }^{2}$ Kyunpook National University Hospital, Daegu, Korea
}

Vitamin D has an important role in calcium and bone metabolism as well as controlling inflammatory responses. Vitamin D also regulates the growth and differentiation of several immune cell types, and inhibits immunomodulatory and anti-inflammatory responses. Vitamin D deficiency increases the loss of innate and adaptive immune function and susceptibility of autoimmune disease and infection, which results in an association with higher risk of sepsis, milk sensitization, respiratory infection or wheeze, type 1 diabetes, multiple sclerosis, and cardiovascular diseases. ${ }^{1)}$ The emerging role of vitamin D in preterm infants involves in pulmonary development and the regulation of lung maturation during the fetal period. ${ }^{2)}$ In animal studies, hypovitaminosis D during pregnancy tends to alter alveolar epithelial mesenchymal signaling, and reducing tracheal diameter, increasing airway resistance, and reducing lung compliance, which results in decreased lung function in fetal mice. ${ }^{3)}$ Activated vitamin D is involved in surfactant synthesis and secretion. ${ }^{3)}$

The major determining factor of neonatal vitamin D level at birth is maternal vitamin D status, as vitamin D transfers to the fetus during third trimester; this suggests that preterm infants are at higher risk of vitamin D deficiency than full-term infants. In Korea, a previous study reported vitamin D status in preterm infants at birth; over 90\% of preterm infants had vitamin D deficiency or insufficiency. ${ }^{4,5}$ Vitamin D levels in late pregnancy and cord blood were associated with the development of wheezing and lower respiratory tract infections in early childhood, the incidence of which could be reduced by vitamin $\mathrm{D}$ supplementation during pregnancy. ${ }^{6}$ In preterm infants (gestational age $\leq 32$ weeks), lower 25-hydroxyvitamin D (25$\mathrm{OHD}$ ) at birth increased the risk of oxygen requirement, use of positive-pressure ventilation in the delivery room, the need for assisted ventilation and the development of respiratory distress syndrome (RDS). ${ }^{7.8}$ Severe maternal and neonatal vitamin D deficiency was shown to increase the risk of bronchopulmonary dysplasia (BPD). ${ }^{9)}$

The study by Kim et al. ${ }^{10)}$ published in the current issue is the first report of the association between low vitamin $D$ levels at birth and neonatal morbidities of very-low-birth-weight (VLBW) infants in Korea. In this report, 80\% of VLBW infants were vitamin D deficient or insufficient. They presented that the clinical factors associated with vitamin D deficiency at birth were season (spring and winter) at birth, older maternal age, and lower birth weight. The clinical outcomes of vitamin D deficiency at birth in VLBW infants were longer duration of hospitalization, longer period of mechanical ventilator and noninvasive oxygen therapy, higher frequency of surfactant therapy, and higher incidence of RDS, BPD and retinopathy of prematurity (ROP). Logistic regression analysis showed that vitamin D deficiency at birth was an independent risk factor of RDS and BPD. Vitamin D deficiency at birth was not correlated with mortality, sepsis, necrotizing enterocolitis (NEC), and other respiratory morbidities including pneumothorax and pulmonary hemorrhage. They did not include data of maternal vitamin D level or individual longitudinal changes in vitamin D status during hospitalization despite administering vitamin $\mathrm{D}$ to participants according to vitamin $\mathrm{D}$ status at birth; therefore, the role of maternal vitamin D level, postnatal vitamin D supplementation
Corresponding author: Sook-Hyun Park, MD, PhD Department of Pediatrics, Kyungpook National University Children's Hospital, School of Medicine, Kyungpook National University, 807, Hoguk-ro, Buk-gu, Daegu 41404, Korea

Tel: +82-53-200-2744

Fax: +82-53-425-6683

E-mail: park_sh@knu.ac.kr

https://orcid.org/0000-0002-4782-1127

Received: 28 November, 2018

Revised: 2 February, 2019

Accepted: 6 April, 2019
Copyright $(\subset 2019$ by The Korean Pediatric Society

This is an open-access article distributed under the terms of the Creative Commons Attribution NonCommercial License (http://creativecommons.org/ licenses/by-nc/4.0/) which permits unrestricted noncommercial use, distribution, and reproduction in any medium, provided the original work is properly cited. 
and duration of vitamin D deficiency associated with respiratory morbidities in preterm infants remains unclear in this report.

The American Academy of Pediatrics recommends 200-400 IU/ day of vitamin $D,{ }^{11)}$ and the European Society of Pediatric Gastroenterology Hepatology and Nutrition recommends 800-1,000 IU/ day in newborns. ${ }^{12)}$ The optimal vitamin $\mathrm{D}$ dose for preterm infants is generally accepted as 200-800 IU/day. Fort et al. ${ }^{13)}$ compared serum 25-OHD concentrations at 28 days after vitamin D intakes of placebo, $200 \mathrm{IU} /$ day, and $800 \mathrm{IU} /$ day in extremely preterm infants (23.0-27.6 weeks of gestation). The 25-0HD concentrations of infants with an intake of $800 \mathrm{IU} /$ day were higher than those of infants with an intake of placebo or $200 \mathrm{IU} /$ day, but above the desired range of $20-60 \mathrm{ng} / \mathrm{mL}$. There were no significant intergroup differences in mortality, rate of weight gain, duration of respiratory support, or neonatal morbidities including BPD, ROP, NEC, or intraventricular hemorrhage (IVH). Increasing the dose of vitamin D was not correlated with a reduction in neurodevelopment impairment or need for oxygen requirement or asthma medication at 2 years of age ${ }^{14)} \mathrm{A}$ previous randomized controlled trial ${ }^{13,14)}$ analyzed the association between 2-year outcomes and vitamin D status at birth but provided no information about 25-OHD levels or vitamin D supplementation between 28 days and 2 years of age. Although vitamin $\mathrm{D}$ status during pregnancy and at birth impacts neonatal lung maturation, changes in vitamin $\mathrm{D}$ status during the trial period may also be associated with respiratory morbidities given that the half-life of 25-OHD is about 2 weeks.

In Korea, the majority of preterm infants are at high risk of vitamin D deficiency. Kim et al. ${ }^{10)}$ reported an association between vitamin D deficiency and a high risk of respiratory morbidities in Korean preterm infants. The early supplementation of $800 \mathrm{IU} /$ day of vitamin D may reduce the incidence of vitamin D deficiency during hospitalization in Korean VLBW infants ${ }^{5}$ but was not associated with neonatal clinical outcomes. In conclusion, vitamin D status at birth may be associated with respiratory morbidities; thus, further studies should be needed to identify the optimal dose and duration of vitamin D supplementation to improve respiratory outcomes in Korean preterm infants.

\section{Conflict of interest}

No potential conflict of interest relevant to this article was reported.

\section{References}

1. Sava F, Treszl A, Hajdú J, Toldi G, Rigó J Jr, Tulassay T, et al. Plasma vitamin D levels at birth and immune status of preterm infants. Immunobiology 2016;221:1289-92.

2. Lykkedegn S, Sorensen GL, Beck-Nielsen SS, Christesen HT. The impact of vitamin D on fetal and neonatal lung maturation. A systematic review. Am J Physiol Lung Cell Mol Physiol 2015;308:L587602.

3. Saadoon A, Ambalavanan N, Zinn K, Ashraf AP, MacEwen M, Nicola $\mathrm{T}$, et al. Effect of prenatal versus postnatal vitamin D deficiency on pulmonary structure and function in mice. Am J Respir Cell Mol Biol 2017;56:383-92.

4. Park SH, Lee GM, Moon JE, Kim HM. Severe vitamin D deficiency in preterm infants: maternal and neonatal clinical features. Korean J Pediatr 2015;58:427-33.

5. Cho SY, Park HK, Lee HJ. Efficacy and safety of early supplementation with $800 \mathrm{IU}$ of vitamin D in very preterm infants followed by underlying levels of vitamin D at birth. Ital J Pediatr 2017;43:45.

6. Christensen N, Søndergaard J, Fisker N, Christesen HT. Infant respiratory tract infections or wheeze and maternal vitamin D in pregnancy: a systematic review. Pediatr Infect Dis J 2017;36:384-91.

7. Onwuneme C, Martin F, McCarthy R, Carroll A, Segurado R, Murphy J, et al. The association of vitamin D status with acute respiratory morbidity in preterm infants. J Pediatr 2015;166:1175-80.e1.

8. Mohamed Hegazy A, Mohamed Shinkar D, Refaat Mohamed N, Abdalla Gaber H. Association between serum $25(\mathrm{OH})$ vitamin D level at birth and respiratory morbidities among preterm neonates. $J$ Matern Fetal Neonatal Med 2018;31:2649-55.

9. Joung KE, Burris HH, Van Marter LJ, McElrath TF, Michael Z, Tabatabai $\mathrm{P}$, et al. Vitamin D and bronchopulmonary dysplasia in preterm infants. J Perinatol 2016;36:878-82.

10. Kim I, Kim SS, Song JI, Yoon SH, Park GY, Lee YW. Association between vitamin D level at birth and respiratory morbidities in verylow-birth-weight infants. Korean J Pediatr 2018 Oct 24 [Epub]. https://doi.org/10.3345/kjp.2018.06632.

11. Abrams SA; Committee on Nutrition. Calcium and vitamin d requirements of enterally fed preterm infants. Pediatrics 2013;131:e1676-83.

12. Agostoni C, Buonocore G, Carnielli VP, De Curtis M, Darmaun D, Decsi T, et al. Enteral nutrient supply for preterm infants: commentary from the European Society of Paediatric Gastroenterology, Hepatology and Nutrition Committee on Nutrition. J Pediatr Gastroenterol Nutr 2010;50:85-91.

13. Fort P, Salas AA, Nicola T, Craig CM, Carlo WA, Ambalavanan N. A Comparison of 3 vitamin $D$ dosing regimens in extremely preterm infants: a randomized controlled trial. J Pediatr 2016;174:132-8.e1.

14. Salas AA, Woodfin T, Phillips V, Peralta-Carcelen M, Carlo WA, Ambalavanan N. Dose-response effects of early vitamin D supplementation on neurodevelopmental and respiratory outcomes of extremely preterm infants at 2 years of age: a randomized trial. Neonatology 2018;113:256-62. 